\title{
High-Flow Nasal Cannula Oxygen Therapy in Adults: Physiological Benefits, Indication, Clinical Benefits, and Adverse Effects
}

\author{
Masaji Nishimura MD PhD
}

\author{
Introduction \\ Adverse Effects of Lack of Humidification \\ Humidification Performance of High-Flow Nasal Cannula Devices \\ Interface \\ Physiological Effect \\ Fraction of Inspired Oxygen \\ PEEP Effect \\ Clinical Trials \\ Hypercapnic Respiratory Failure \\ Hypoxemic Respiratory Failure \\ Postextubation \\ Preintubation Oxygenation \\ Acute Heart Failure \\ Sleep Apnea \\ Other Conditions \\ Adverse Effects \\ Contraindication \\ Conclusions
}

\begin{abstract}
High-flow nasal cannula (HFNC) oxygen therapy is carried out using an air/oxygen blender, active humidifier, single heated tube, and nasal cannula. Able to deliver adequately heated and humidified medical gas at flows up to $60 \mathrm{~L} / \mathrm{min}$, it is considered to have a number of physiological advantages compared with other standard oxygen therapies, including reduced anatomical dead space, PEEP, constant $\mathrm{F}_{\mathrm{IO}}$, and good humidification. Although few large randomized clinical trials have been performed, HFNC has been gaining attention as an alternative respiratory support for critically ill patients. Published data are mostly available for neonates. For critically ill adults, however, evidence is uneven because the reports cover various subjects with diverse underlying conditions, such as hypoxemic respiratory failure, exacerbation of COPD, postextubation, preintubation oxygenation, sleep apnea, acute heart failure, and conditions entailing do-not-intubate orders. Even so, across the diversity, many published reports suggest that HFNC decreases breathing frequency and work of breathing and reduces the need for respiratory support escalation. Some important issues remain to be resolved, such as definitive indications for HFNC and criteria for timing the starting and stopping of HFNC and for escalating treatment. Despite these issues, HFNC has emerged as an innovative and effective modality for early treatment of adults with respiratory failure with diverse underlying diseases. Key words: noninvasive ventilation; high-flow oxygen therapy; escalation; randomized; controlled trials; humidification. [Respir Care 2016;61(4):529-541. (C) 2016 Daedalus Enterprises]
\end{abstract}




\section{Introduction}

Respiratory support is applied to maintain adequate oxygenation and alveolar ventilation, and the first-line treatment for hypoxemic respiratory failure is supplemental oxygen. During spontaneous breathing, inspired air passes through the nose, pharynx, larynx, and trachea. Due to the great ability of the human nose and upper airway to warm and humidify inspired gas, on the way down to the alveoli, inspired air is warmed up to body temperature and fully saturated with water vapor. The nose and upper airway are also excellent radiators: During natural breathing, even when the ambient air is cold and dry, they are capable of maintaining temperature in the oropharyngeal space. ${ }^{1}$ Supplemental oxygen, however, is not usually humidified when administered at low flow. Bubble humidifiers are sometimes used for humidifying medical gas delivered to spontaneously breathing patients, but the absolute humidity of the emergent gas remains low. ${ }^{2}$ Dry or poorly humidified medical gas may elicit patient complaints, such as dry nose, dry throat, and nasal pain, and consequent poor tolerance of oxygen therapy. Unconditioned gas increases airway resistance to protect the lungs from dry or cold inspired air by reducing the air flow in the upper airways and trachea. ${ }^{3,4}$ Breathing dry air is known to reduce nasal mucoclliary clearance. ${ }^{5}$ Using conventional devices, oxygen flow is limited to no more than $15 \mathrm{~L} / \mathrm{min}$. Meanwhile, the required inspiratory flow for patients with respiratory failure varies widely in a range from 30 to $>120 \mathrm{~L} / \mathrm{min}^{6}{ }^{6}$ The difference between patient inspiratory flow and delivered flow is large with conventional oxygen devices, and $\mathrm{F}_{\mathrm{IO}_{2}}$ is inconstant and generally lower than expected. . $^{7}$

Administered via an air/oxygen blender, active heated humidifier, single heated circuit, and nasal cannula, highflow nasal cannula (HFNC) oxygen therapy has been gaining attention as an alternative means of respiratory support for critically ill patients. The air/oxygen blender is set for $\mathrm{F}_{\mathrm{IO}_{2}}$ between 0.21 and 1.0 at up to $60 \mathrm{~L} / \mathrm{min}$ flow (Fig. 1 ). ${ }^{9}$ Heated and humidified by the active humidifier, the gas is delivered through the heated circuit. Warm and adequately humidified gas delivered at high flow has apparent beneficial physiological effects. Although recently, results of large randomized clinical trials have been reported, ${ }^{10,11}$

The author is affiliated with the Department of Emergency and Critical Care Medicine, Tokushima University Graduate School, Kuramoto, Tokushima, Japan.

Dr Nishimura has disclosed no conflicts of interest.

Correspondence: Masaji Nishimura MD PhD, Emergency and Critical Care Medicine, Tokushima University Graduate School, 3-18-15 Kuramoto, Tokushima 770-8503, Japan. E-mail: nmasaji@ tokushima-u.ac.jp.

DOI: $10.4187 /$ respcare.04577

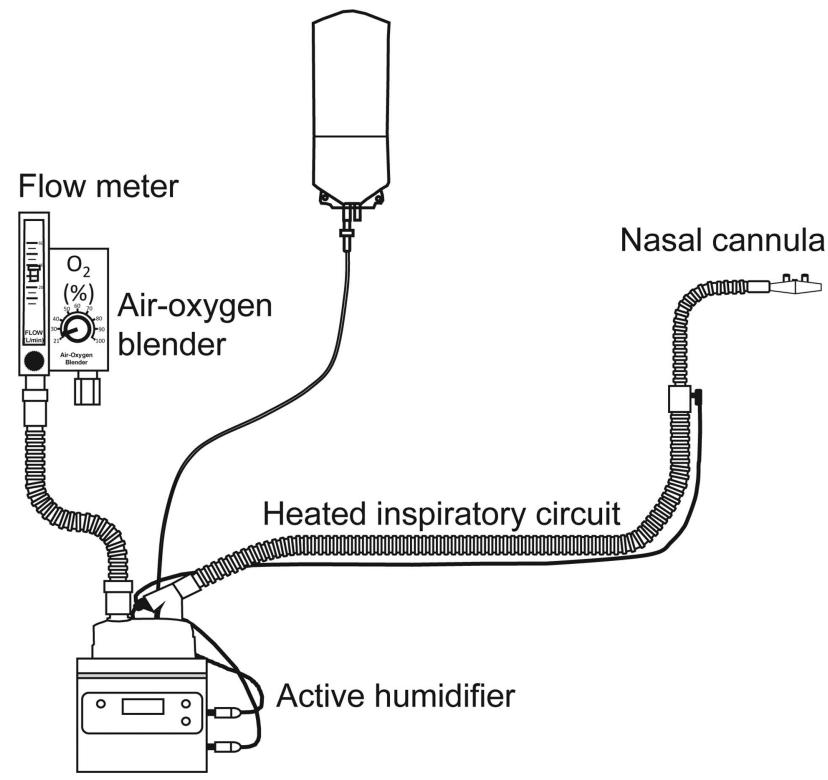

Fig. 1. Basic setup for high-flow nasal cannula oxygen delivery. An air-oxygen blender, allowing from 0.21 to $1.0 \mathrm{~F}_{1 \mathrm{O}_{2}}$, generates up to $60 \mathrm{~L} / \mathrm{min}$ flow. The gas is heated and humidified through an active heated humidifier and delivered via a single-limb heated inspiratory circuit. The patient breathes adequately heated and humidified medical gas through large-diameter nasal cannulas. (Modified from Reference 9.)

even before those trials, HFNC was widely applied to critically ill patients with diverse underlying diseases. HFNC provides medical gases at higher flow and with more predictable $\mathrm{F}_{\mathrm{IO}_{2}}$ than with other devices. Through such an open circuit, we cannot expect high end-expiratory pressure, but it reportedly creates PEEP and may increase end-expiratory lung volume (EELV). ${ }^{12}$

Currently, to ensure adequate alveolar ventilation, minute ventilation is manipulated during invasive or noninvasive ventilatory support. For patients with COPD exacerbation, noninvasive ventilation (NIV) has become the preferred primary modality for respiratory support because it boosts inspiratory tidal volume $\left(\mathrm{V}_{\mathrm{T}}\right)$ and maintains adequate alveolar ventilation. ${ }^{13}$ Due to poor mask tolerance, however, NIV is inapplicable to some patients. ${ }^{14}$ The major difference between NIV and HFNC is the interface. Whereas NIV interfaces increase anatomical dead space, HFNC actually decreases dead space. When the circuit is so open, however, without effective inspiratory push or expiratory pull, HFNC cannot actively enhance $\mathrm{V}_{\mathrm{T}}$. Besides decreasing anatomical dead space, HFNC also improves alveolar ventilation. In view of these advantages that cover some of the inadequacies of conventional oxygen delivery systems and apparent beneficial physiological effects, the use of HFNC for critically ill adults has been dramatically increasing. The simplicity and excellent tolerance of the system is especially attractive. HFNC is simple and easy, it makes the start of respiratory support 
earlier, and it has a possibility of decreasing the use of mechanical ventilation. ${ }^{15}$

\section{Adverse Effects of Lack of Humidification}

Dry gas may have diverse adverse effects on the respiratory system. In dogs, breathing dry air causes complete cessation of the flow of tracheal mucus ${ }^{16}$ and, in cultured human epithelial cells, it causes acute damage and inflammation. ${ }^{17}$ In guinea pigs, it induces widespread loss of the cilia, associated with detachment or sloughing of the epithelium, subepithelial vascular congestion, edema, and cellular infiltration. ${ }^{18}$ It is also well-known that cold air induces bronchoconstriction in patients with asthma. ${ }^{19}$ Airway resistance increases to protect the lungs from the challenge of dry and cold gas by reducing the air flow in the upper airways and trachea. ${ }^{3,4}$ Breathing dry air causes excessive water loss by the nasal mucosa ${ }^{20}$ which may in turn reduce the nasal mucoclliary clearance rate via changes in the rheological properties or adhesiveness of nasal mucus and/or slowing of ciliary pulses. ${ }^{5}$

Unwarmed and dry gas may have adverse effects on patients with respiratory failure. Conventional oxygen devices are associated with mask discomfort, nasal dryness, oral dryness, eye irritation, nasal and eye trauma, and gastric distention. ${ }^{19,21}$ Nasal obstruction of patients with obstructive sleep apnea ${ }^{22}$ receiving CPAP is inflammatory in origin, and the addition of heated humidification decreases nasal resistance and mucosal inflammation. ${ }^{23}$ Since NIV delivers medical gas at high flow, oral dryness and patient discomfort are likely with poorly conditioned gases. ${ }^{24}$ The absolute humidity of gas delivered through oronasal masks during NIV, which is affected by humidifier settings and amount of leakage, varies among patients at equivalent humidifier settings. Occasionally, high-flow dry gas results in inspissated secretions that cause life-threatening airway obstruction..$^{25}$ In mechanically ventilated patients, when an endotracheal or tracheostomy tube bypasses the upper airway, where most humidification would naturally occur, poor humidification increases in the incidence of endotracheal tube occlusion. ${ }^{26}$ As little as 5 min of delivery of ambient gas directly at the trachea can cause a significant decrease in pulmonary compliance and conductance in infants. ${ }^{27}$

By contrast, conditioning of the gas minimizes airway constriction, reduces the work of breathing (WOB), improves mucociliary function, ${ }^{5}$ facilitates clearance of secretions, and is associated with less atelectasis, resulting in a good ventilation/perfusion ratio and better oxygenation. Long-term humidification therapy statistically significantly reduces days of exacerbation, increases time to first exacerbation, and generally improves lung function and quality of life in subjects with COPD and bronchiectasis. ${ }^{28}$

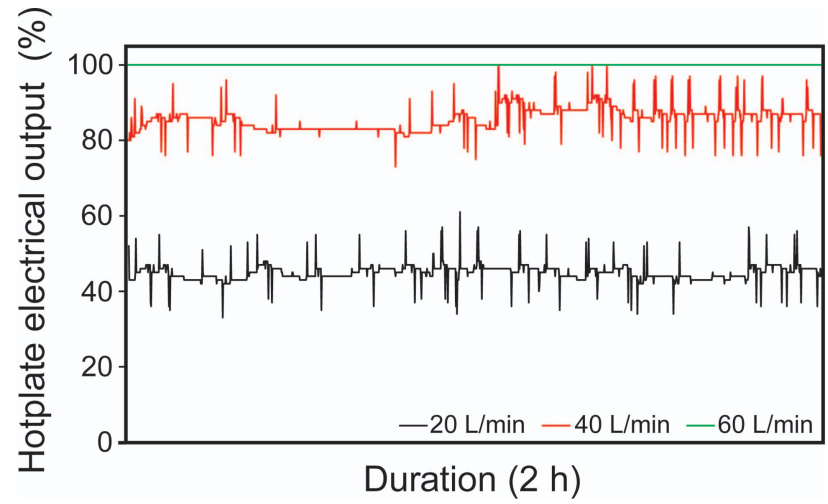

Fig. 2. Electrical output of the hotplate of an MR850 heated humidifier with an MR290 water chamber (both from Fisher \& Paykel). The MR850 was set to maintain temperature at the water chamber outlet at $37^{\circ} \mathrm{C}$ and at the distal end of the inspiratory limb at $40^{\circ} \mathrm{C}$. When flow was $60 \mathrm{~L} / \mathrm{min}$, electrical output was always $100 \%$.

\section{Humidification Performance of HFNC Devices}

Because HFNC delivers medical gas at up to $60 \mathrm{~L} / \mathrm{min}$ flow, it has the potential to cause the same adverse effects of inadequate humidification as NIV. In practice, however, HFNC is considered to deliver well-conditioned gas to patients. As an open system with constant flow, HFNC is able to deliver a constant amount of vapor. Humidification is influenced by many factors, and only when HFNC flow is higher than the inspiratory flow of a patient with optimally positioned nasal prongs is it reasonable to expect that the patient is inspiring well-conditioned gas. During spontaneous breathing, however, $\mathrm{V}_{\mathrm{T}}$ and inspiratory flow varies, ${ }^{29}$ and, if HFNC flow is less than patient inspiratory flow, the patient will inspire atmospheric air. When HFNC flow is sufficiently high, the absolute humidity of inspired gas is unlikely to be a problem. Even so, we should bear in mind that HFNC devices usually incorporate a heated humidifier into the mechanical ventilation system, and the capability of such systems to create adequate vapor for high flow remains unclear. Figure 2 shows the electrical output of the hotplate of an MR850 heated humidifier with an MR290 water chamber (both from Fisher \& Paykel, Auckland, New Zealand). At a flow of $60 \mathrm{~L} / \mathrm{min}$, electrical output was constantly $100 \%$, and absolute humidity was lower at $60 \mathrm{~L} / \mathrm{min}$ than at $40 \mathrm{~L} / \mathrm{min}^{30}$ When HFNC is applied at very high flow, we should be aware that humidification may be less than adequate. The water chamber of the AIRVO 2 (also from Fisher \& Paykel) is larger than that of the MR290, and its ability to deliver vapor is greater than the Optiflow, composed of the MR290 and MR850. 30

HFNC devices usually incorporate a heated circuit to avoid losing vapor in condensation, although some condensation is inevitable. When patients receiving nasal CPAP 
complain of symptoms in the nose and pharynx, heated humidification may be applied to reduce the adverse effects of ventilation; once this is done, condensation may accumulate in the circuit, and subsequent spraying of water droplets into the nostril may disturb sleep. Low ambient temperature is also likely to increase the amount of condensation. This is true also for HFNC devices: The amount of condensation depends on atmospheric temperature. Investigating factors influencing the amount of condensation, Chikata et $\mathrm{al}^{31}$ found that ambient air temperature, flow, and the technical design of the ventilator delivery tube influenced the amount of condensation. Ambient air temperature was the most prominent factor. Even with HFNC, the condition of the delivered gas may not necessarily be $100 \%$ humidity at $37^{\circ} \mathrm{C}$. The breathing pattern of the patient, the delivered flow of HFNC, and the type of delivery device can influence humidification during HFNC. As always, the position of HFNC nasal prongs is also important.

\section{Interface}

During the past 2 decades, the utilization of NIV has been an important development in the field of respiratory support. Because it enhances inspiratory $\mathrm{V}_{\mathrm{T}}$ and maintains adequate alveolar ventilation, for patients with COPD exacerbation, NIV has become the preferred primary modality for respiratory support. ${ }^{13}$ Even without rigorously established evidence, the application of NIV for other respiratory diseases has also been gaining ground. No studies have reported a $100 \%$ success rate, and the severity of illness and the initial responses to NIV are the main predictors of NIV outcome. Furthermore, to ensure good results, an appropriate interface is more important than the ventilation mode. ${ }^{32}$ Oronasal masks, nasal masks, and hoods are most commonly used for NIV. Oronasal masks are usually tried first because they ensure the effects of NIV better than other interfaces. Unfortunately, this type of mask is not comfortable, and many patients find it hard to tolerate. It is also associated with a relatively high incidence of air leakage. ${ }^{33}$ Also, skin lesions at the nose induced by long-term use of this device may result in frequent treatment interruptions and discontinuation. ${ }^{34}$ When administering nasal CPAP to preterm infants and neonates, nasal trauma is a major issue. Since the interface of nasal CPAP requires secure fixing without leaks, the reported incidence of pressure ulcers ranges from 15 to $100 \% .35$ The same study reported less nasal trauma with HFNC, an open system in which leaks are not a concern. Adult patients also show less skin damage with HFNC than with bi-level positive airway pressure treatment. ${ }^{11}$ For subjects with acute hypoxic respiratory failure, Schwabbauer et al ${ }^{36}$ randomly applied HFNC, NIV, and air-entrainment mask delivery for 30 min each. They found that HFNC offers a better balance between oxygenation and comfort than NIV or air-entrainment mask delivery and seemed to be well tolerated by subjects. Granted, the observation period was of short duration, but other studies have also reported that HFNC is more comfortable than other modes of delivery, resulting in extended tolerance of HFNC support. For subjects disallowed intubation, Peters et al ${ }^{37}$ applied HFNC for 2-144 $\mathrm{h}$ and found that HFNC can provide adequate oxygenation for many subjects with hypoxemic respiratory failure. Because of the difficulties of managing NIV over long periods, HFNC is a promising alternative to NIV for do-not-intubate patients. Here, the outstanding characteristics of HFNC are excellent acceptance and tolerability.

\section{Physiological Effect}

In $\mathrm{HFNC}$, at flow of up to $60 \mathrm{~L} / \mathrm{min}$, gas from an air/oxygen blender is heated and humidified with an active humidifier and subsequently delivered through a heated circuit. Again, it must be borne in mind that this is an open system: HFNC neither pushes nor pulls gas; consequently, it does not facilitate $V_{T}$ and minute ventilation. Despite this, high flow of adequately heated and humidified gas is considered to have a number of physiological effects. High flow washes out carbon dioxide in anatomical dead space. Figure 3 shows data, from several clinical studies, for breathing frequency and $\mathrm{P}_{\mathrm{aCO}}$ with comparative oxygen devices and HFNC. Although the underlying diseases differed in these studies, breathing frequencies decreased across the board. Since there was no difference in $\mathrm{P}_{\mathrm{aCO}_{2}}$ between HFNC and conventional oxygen devices, it can be assumed that alveolar ventilation was similar. All subjects breathed spontaneously, but $\mathrm{V}_{\mathrm{T}}$ was not measured, and minute volume could not be evaluated. Meanwhile, using respiratory inductive plethysmography to compare thoraco-abdominal synchrony, Itagaki et $\mathrm{al}^{38}$ found that thoraco-abdominal synchrony was better with HFNC than with face mask delivery. Since $V_{T}$ (calculated from rib cage and abdominal measurements) was constant and breathing frequency was reduced, minute ventilation was lower with HFNC. Constant $\mathrm{P}_{\mathrm{aCO}}$ indicated steady alveolar ventilation. ${ }^{38}$ The findings also suggest less ventilation of dead space (minute volume - alveolar ventilation). Other studies, although lacking $\mathrm{P}_{\mathrm{aCO}}$ values, have reported reduced breathing frequency with HFNC. ${ }^{39-42}$ Sztrymf ${ }^{39}$ et al observed the effects of HFNC on acute respiratory failure subjects with $\mathrm{S}_{\mathrm{pO}_{2}}<92 \%$ and oxygen flow $>9$ $\mathrm{L} / \mathrm{min}$. With HFNC, thoraco-abdominal synchrony improved in $30 \mathrm{~min}$.

Just why HFNC improves thoraco-abdominal synchrony is not clear, but it is fair to surmise that, with less dead space, WOB decreases, and this contributes to lower breath- 


\section{HFNC IN ADULTS}
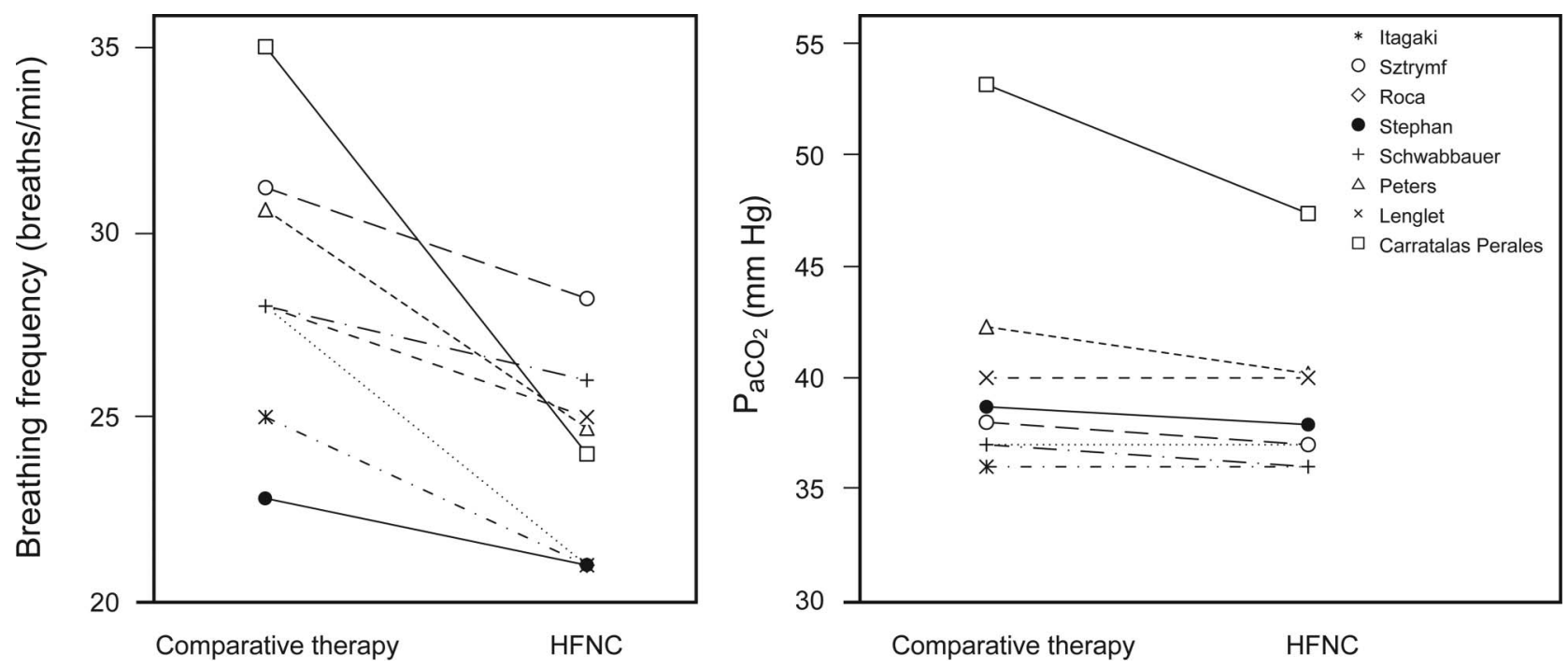

Fig. 3. Breathing frequency and $\mathrm{P}_{\mathrm{aCO}}$ : comparison between high-flow nasal cannula oxygen therapy (HFNC) and comparative therapies in 8 studies. Left: Difference of breathing frequency between comparative therapy and HFNC. In all studies, breathing frequency with HFNC was lower. Right: Difference of $\mathrm{P}_{\mathrm{aCO}_{2}}$. Here, no statistically significant differences between the therapies are apparent.

ing frequency. In a lung-injured animal model, $\mathrm{P}_{\mathrm{aCO}_{2}}$ decreased as HFNC flow increased, and greater escape of gas more effectively decreased $\mathrm{P}_{\mathrm{aCO}}$. Such results suggest that HFNC effectively washes out carbon dioxide. ${ }^{43}$ In infants and neonates, the effect of HFNC on WOB was compared with that of nasal CPAP. When retropharyngeal pressure was the same, the breathing pattern and WOB did not differ between HFNC and nasal CPAP. ${ }^{44}$ In preterm neonates $(<2.0 \mathrm{~kg}), \mathrm{HFNC}$ at 3,4 , and $5 \mathrm{~L} / \mathrm{min}$ and $6 \mathrm{~cm} \mathrm{H}_{2} \mathrm{O}$ of nasal CPAP did not reveal differences in WOB. ${ }^{45}$ de Jong et al evaluated asynchronous breathing by respiratory inductive plethysmography. Both HFNC at $5 \mathrm{~L} / \mathrm{min}$ and nasal $\mathrm{CPAP}$ at 5 and $6 \mathrm{~cm} \mathrm{H}_{2} \mathrm{O}$ improved phase angle, whereas there was a lack of a clinically meaningful difference between the devices. ${ }^{46}$ Pham et $\mathrm{al}^{47}$ measured electrical activity of the diaphragm in infants with bronchiolitis. HFNC at $2 \mathrm{~L} / \mathrm{kg}$ increased EELV probably because of reduction of micro-atelectasis due to the CPAP effect. These studies suggest that HFNC increases EELV due to the CPAP effect resulting in decrease of WOB. Although all of these studies have been conducted on infants and neonates, this may be true also in adults.

HFNC is the only noninvasive respiratory support that does not increase dead space. With an oxygen mask, especially at low flow, carbon dioxide is rebreathed. NIV interfaces also increase dead space, and volume is especially added by hood-type CPAP systems. To maintain $\mathrm{P}_{\mathrm{aCO}_{2}}$ (alveolar ventilation), in other modes, minute volume has to increase, either through more frequent breathing or increased $\mathrm{V}_{\mathrm{T}}$ or both. In other words, masks and hoods are likely to increase WOB in patients with respiratory failure. Worthy of special mention, during sponta- neous breathing without volume or pressure support or both, HFNC can decrease WOB.

\section{Fraction of Inspired Oxygen}

Physiologically, inspiratory flow is not constant, and $\mathrm{V}_{\mathrm{T}}$ (inspiratory flow) varies breath-by-breath. ${ }^{29,48}$ This means that the difference between inspiratory flow and delivered oxygen flow varies both in one breath and breath-by-breath. As far as we know, ventilation equipment algorithms work on the assumption that all delivered oxygen is inspired, but, because oxygen masks have holes to prevent carbon dioxide rebreathing, the patient does not necessarily inspire all delivered oxygen. Actual $\mathrm{F}_{\mathrm{IO}_{2}}$ is not stable during low-flow oxygen delivery and is generally much lower than predicted by equipment algorithms $\mathrm{s}^{7,8}$ : in particular, with face masks, $\mathrm{F}_{\mathrm{IO}_{2}}$ was found to be higher during mouthopen breathing than during mouth-closed breathing and lower during nasal cannula delivery. With HFNC, patients mainly inspire delivered gas via nasal prongs, and delivered flow is much higher than with conventional oxygen delivery systems: During HFNC, especially at high flow, actual $\mathrm{F}_{\mathrm{IO}_{2}}$ was close to calculated (predicted) $\mathrm{F}_{\mathrm{IO}_{2}}$. Measuring hypopharyngeal oxygraphy, capnography, and pressure, Ritchie et $\mathrm{al}^{49}$ found that during nose breathing at rest, $>30 \mathrm{~L} / \mathrm{min}$, measured $\mathrm{F}_{\mathrm{IO}_{2}}$ was close to delivered $\mathrm{F}_{\mathrm{IO}_{2}}$. Wettstein et al ${ }^{50}$ compared $\mathrm{F}_{\mathrm{IO}_{2}}$ in healthy volunteers breathing with mouths opened and closed: $\mathrm{F}_{\mathrm{IO}_{2}}$ was higher with mouth-open breathing. Because high flow allows oxygen to completely suffuse the nasal cavity during exhalation, breathing with the mouth open may result in a larger anatomic reservoir. 


\section{PEEP Effect}

Although HFNC is an open system, high flow from the nasal cannula offers resistance against expiratory flow and increases airway pressure. In an in vitro neonate model of HFNC, airway pressure increased as flow increased. ${ }^{51}$ Mean upper airway pressure with mouth closed showed increasing pressure with increasing delivered gas flow. ${ }^{39}$ In postoperative subjects, as inspiratory flow increased, airway pressure increased, $1.52 \pm 0.7,2.21 \pm 0.8$, and $3.1 \pm 1.2 \mathrm{~cm} \mathrm{H}_{2} \mathrm{O}$ at 40,50 , and $60 \mathrm{~L} / \mathrm{min}$ of flow. ${ }^{49}$ Comparing HFNC and face mask delivery, Parke et al ${ }^{52}$ measured nasopharygeal pressure in post-cardiac surgery subjects: Nasopharyngeal pressure at $35 \mathrm{~L} / \mathrm{min}$ flow, during HFNC, increased to $2.7 \pm 1.04 \mathrm{~cm} \mathrm{H}_{2} \mathrm{O}$ with the mouth closed and $1.2 \pm 0.76 \mathrm{~cm} \mathrm{H}_{2} \mathrm{O}$ with the mouth open, but with the face mask, it remained at around zero. Other authors have also reported positive pharyngeal pressure, with HFNC affected by sex, body mass index, mouth closed or opened, and flow. ${ }^{12,42,49,53,54}$ With mouth closed, pharyngeal pressure increases as flow increases. With mouth open, even at $60 \mathrm{~L} / \mathrm{min}$ flow, pharyngeal pressure remains below $3 \mathrm{~cm} \mathrm{H}_{2} \mathrm{O} .{ }^{52}$ By contrast with $\mathrm{F}_{\mathrm{IO}_{2}}$, mouth opening or closing significantly influences positive pharyngeal pressure.

Although pharyngeal pressure increases with HFNC, it is usually around $3 \mathrm{~cm} \mathrm{H}_{2} \mathrm{O}$, and it remains unclear whether HFNC increases lung volume. Evaluating EELV, Corley et $\mathrm{al}^{42}$ found EELV was greater with HFNC than with low-flow oxygen therapy, the effect being more pronounced in patients with higher body mass index. Using electrical lung impedance tomography on healthy subjects in supine and in prone postures, Riera et $\mathrm{al}^{54}$ found that in either position, EELV was greater when HFNC was applied. Recently, Parke et al ${ }^{55}$ measured EELV at up to $100 \mathrm{~L} / \mathrm{min}$ of HFNC in healthy volunteers. Airway pressure and EELV increased linearly with increased gas flow. ${ }^{55}$

\section{Clinical Trials}

As an open system, HFNC is easy to apply and easy to use (requiring only setting $\mathrm{F}_{\mathrm{IO}_{2}}$ and flow). It is generally comfortable for patients and it is not usually interrupted or discontinued because of intolerance. ${ }^{39}$ As Figure 2 and Table 1 show, despite the lack of a body of rigorously established evidence to guide its use, it is becoming usual to apply HFNC for diverse underlying conditions. ${ }^{9}$

\section{Hypercapnic Respiratory Failure}

Hypercapnic respiratory failure is a frequently encountered problem..$^{75}$ Patients with this condition are unsuitable for mechanical ventilation, and NIV has been the primary modality for their respiratory support. ${ }^{76}$ Because of poor mask tolerance, however, for some patients it is inappropriate. ${ }^{77,78}$ More easily tolerated, HFNC can often be applied to successfully manage hypercapnic respiratory failure in patients unable to tolerate conventional NIV. ${ }^{79}$ Although HFNC does not provide active inspiratory support, compared with unaided breathing, in COPD subjects, HFNC increased $\mathrm{V}_{\mathrm{T}} \cdot{ }^{80}$ Investigating the effects of HFNC on COPD subjects with chronic hypercapnic respiratory failure, Nilius et al ${ }^{66}$ found that individual responses to HFNC varied: For some, breathing frequency decreased, and for others, $\mathrm{P}_{\mathrm{aCO}_{2}}$ decreased. HFNC also increases exercise capacity for stable COPD subjects, providing better oxygenation than spontaneous breathing. ${ }^{81}$ HFNC is a highly promising therapy for some types of hypercapnic respiratory failure.

\section{Hypoxemic Respiratory Failure}

Maintaining adequate oxygenation depends on properly managing $\mathrm{F}_{\mathrm{IO}_{2}}$ and functional residual capacity (usually with PEEP). With conventional oxygen delivery systems, however, $\mathrm{F}_{\mathrm{IO}_{2}}$ values are difficult to control and are usually lower than expected. For patients with hypoxemic respiratory failure, can HFNC help in maintaining stable $\mathrm{F}_{\mathrm{IO}_{2}}$ and positive pharyngeal pressure? HFNC literally delivers high flow, and actual $\mathrm{F}_{\mathrm{IO}_{2}}$ values are usually close to delivered $\mathrm{F}_{\mathrm{IO}_{2}}{ }^{49}$ Although the cannula is part of an open system, high flow from the nasal cannula meets resistance from patient expiration, and pressure in the pharynx increases. ${ }^{49,52}$

Investigating the efficiency, safety, and outcome of HFNC in ICU subjects with acute respiratory failure (ARF), Sztrymf et al ${ }^{39}$ replaced about $15 \mathrm{~L} / \mathrm{min}$ oxygen flow via face mask with HFNC $49 \pm 9 \mathrm{~L} / \mathrm{min}$. This reduced breathing frequency, heart rate, dyspnea score, and supraclavicular retraction and improved thoraco-abdominal synchrony and $\mathrm{S}_{\mathrm{pO}_{2}}$. Duration of HFNC was $2.8 \pm 1.8$ days (max. $7 \mathrm{~d}$ ), and HFNC was not stopped because of intolerance. Sztrymf et $\mathrm{al}^{39}$ also investigated the effects of HFNC on ARF due to community-acquired pneumonia and sepsis. After changing $15 \mathrm{~L} / \mathrm{min}$ oxygen flow via face mask with HFNC $40 \mathrm{~L} / \mathrm{min}$, breathing frequency was reduced, and oxygenation improved. After a median delay of $17.5 \mathrm{~h}$ of HFNC therapy, 6 of 20 subjects (30\%) were subsequently intubated due to septic shock, gastrointestinal hemorrhage, and worsening pneumonia. ${ }^{40} \mathrm{HFNC}$ has also been applied to patients with mild to moderate hypoxemic respiratory failure in a cardiothoracic ICU ${ }^{12}$ and emergency room. ${ }^{69,82,83}$ HFNC can be regarded as a first-line treatment for patients with mild to moderate hypoxemic ARF.

Because HFNC does not ensure positive pharyngeal pressure, it has not been recommended for severe hypoxemic ARF. Rello et al ${ }^{84}$ applied HFNC to subjects with acute hypoxemic respiratory failure due to influenza A/H1N1: 9 
Table 1. Application of High-Flow Nasal Cannula

\begin{tabular}{|c|c|c|c|c|c|}
\hline $\begin{array}{l}\text { Patients or } \\
\text { Subjects, } n\end{array}$ & Underlying Conditions & Comparators & $\begin{array}{l}\text { Flow, } \\
\mathrm{L} / \mathrm{min}\end{array}$ & Main Results & First Author \\
\hline \multicolumn{6}{|l|}{ Case reports } \\
\hline 1 & Fiberoptic bronchoscopy in ICU & & & & $\operatorname{Diab}^{56}$ \\
\hline 1 & Reperfusion pulmonary edema & & & & Moriyama $^{57}$ \\
\hline 1 & Pulmonary fibrosis and DNR & & & & Boyer $^{58}$ \\
\hline 1 & Dementia & & & & Calvano ${ }^{59}$ \\
\hline 1 & ARF of neuromuscular origin & & & & Diaz-Lobato $^{60}$ \\
\hline \multicolumn{6}{|l|}{ Case series } \\
\hline 5 & Acute cardiogenic pulmonary edema & $\begin{array}{l}\mathrm{VM} 15 \\
\mathrm{~L} / \mathrm{min}\end{array}$ & 60 & f decreased, dypnea improved & Carratalá Perales ${ }^{22}$ \\
\hline 5 & Oxygenation during BAL & & & & Miyagi61 \\
\hline \multicolumn{6}{|c|}{ Retrospective } \\
\hline 37 & $\mathrm{ARF}$ in lung transplant recipients & SOT & & ETI: SOT $89 \%$, HFNC $59 \%$ & Roca $^{62}$ \\
\hline 45 & $\mathrm{ARF}$ in hematologic malignancies & & & 15: successful, 30: ETI & Lee $^{63}$ \\
\hline 67 & Post-extubation & NRM & & Re-intubation HFNC (1) < NRM (6) & Brotfain ${ }^{64}$ \\
\hline 50 & DNR/DNI order (hypoxemic RF) & & & HFNC was well-tolerated, duration $30 \mathrm{~h}$ (range 2-144) & Peters ${ }^{37}$ \\
\hline 175 & HFNC failure & & & $\begin{array}{l}\text { Late failure worsened ICU mortality, extubation success, and } \\
\text { VFDs }\end{array}$ & Kang 65 \\
\hline \multicolumn{6}{|c|}{$\begin{array}{l}\text { Sequential } \\
\text { intervention }\end{array}$} \\
\hline 14 & Hypoxemic ARF & $\underset{\text { VM }}{\text { NIV and }}$ & 55 & $\begin{array}{l}\text { Dyspnea score, HFNC }<\text { VM }<\text { NIV, subject rating: } \\
\text { HFNC }>\text { VM }>\text { NIV }\end{array}$ & Schwabbauer ${ }^{36}$ \\
\hline & & & & f HFNC $<$ NIV, oxygenation NIV $>$ HFNC $>$ VM & \\
\hline 17 & Severe COPD and hypercapnic RF & LFO & & $\mathrm{f}$ decreased with $\mathrm{HFNC}$ & Nilius $^{66}$ \\
\hline 12 & OSA & & 20 & Apnea-hypopnea and arousal index decreased & McGinley ${ }^{67}$ \\
\hline 20 & Post-cardiac surgery & LFO & & EELI increased, $P_{a w}$ increased, $f$ decreased, $P / F$ increased & Corley $^{42}$ \\
\hline 10 & Heart failure (NYHA III) & & $20 / 40$ & IVC reduced & Roca $^{68}$ \\
\hline 17 & ARF in ER & & 40 & $\begin{array}{l}8 \text { discharged from ER, } 9 \text { admitted to ICU and among them } 2 \\
\text { intubated }\end{array}$ & Lenglet ${ }^{69}$ \\
\hline \multicolumn{6}{|c|}{ 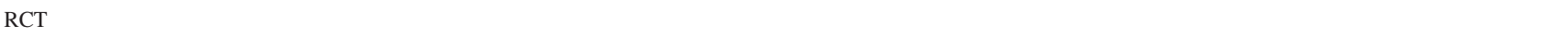 } \\
\hline 20 & ARF & FM & $20-30$ & f decreased, comfort and oxygenation were better with HFNC & Roca $^{41}$ \\
\hline 60 & Mild-moderate hypoxemic ARF & FM & 35 & More HFNC succeeded. NIV: HFNC $3 / 29$ (10\%), FM 8/27 (30\%) & Parke $^{12}$ \\
\hline 45 & Indications for BFS & $\mathrm{VM}$ & $40 / 60$ & 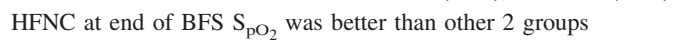 & Lucangelo $^{71}$ \\
\hline 155 & Post-cardiac surgery, BMI $\geq 30$ & SOT & $35-50$ & Respiratory support escalation 5 in standard, 3 in HFNC & Corley $^{72}$ \\
\hline 310 & Hypoxemic RF & $\begin{array}{l}\text { SOT and } \\
\text { NIV }\end{array}$ & 50 & VFD increased, mortality improved, $\mathrm{f}$ & Frat $^{10}$ \\
\hline 830 & After cardiothoracic surgery & BPAP & 50 & $\begin{array}{l}\text { Treatment failure ns, ICU mortality ns, Skin breakdown: } \\
\text { BiPAP }>\text { HFNC }\end{array}$ & Stephan ${ }^{11}$ \\
\hline 105 & Post-extubation & $\mathrm{VM}$ & 50 & $\begin{array}{l}\text { LOS_ICU, ICU mortality ns, re-intubation } 4 \% \text { vs } 21 \% \text {, timing of } \\
\text { re-intubation na }\end{array}$ & Maggiore $^{73}$ \\
\hline 340 & Post-cardiac surgery, post-extubation & $\mathrm{NC}$ & & LOS ICU ns, escalation of respiratory support $27.8 \%$ vs $45 \%$ & Parke $^{70}$ \\
\hline 124 & Hypoxemic RF requiring ETI & FM & 60 & Lowest saturation, severe desaturation $(<80 \%) \mathrm{ns}$ & Vourc'h ${ }^{74}$ \\
\hline \multicolumn{6}{|c|}{$\overline{\text { DNR }=\text { do-not-resuscitate }}$} \\
\hline \multicolumn{6}{|c|}{$\mathrm{ARF}=$ acute respiratory failure } \\
\hline \multicolumn{6}{|c|}{$\mathrm{VM}=$ Venturi mask } \\
\hline \multicolumn{6}{|c|}{$\mathrm{f}=$ breathing frequency } \\
\hline \multicolumn{6}{|c|}{$\mathrm{BAL}=$ bronchoalveolar lavage } \\
\hline \multicolumn{6}{|c|}{ SOT $=$ standard oxygen therapy } \\
\hline \multicolumn{6}{|c|}{$\mathrm{ETI}=$ endotracheal intubation } \\
\hline \multirow{2}{*}{\multicolumn{6}{|c|}{$\begin{array}{l}\text { HFNC }=\text { high-flow nasal cannula } \\
\text { NRM }=\text { non-rebreathing mask }\end{array}$}} \\
\hline & & & & & \\
\hline \multicolumn{6}{|c|}{ DNI $=$ do-not-intubate } \\
\hline \multicolumn{6}{|c|}{$\mathrm{VFD}=$ ventilator-free day } \\
\hline \multicolumn{6}{|c|}{ NIV = noninvasive ventilation } \\
\hline $\mathrm{RF}=$ respirator & & & & & \\
\hline $\mathrm{BPAP}=$ bi-leve & positive airway pressure & & & & \\
\hline $\mathrm{NC}=$ nasal can & & & & & \\
\hline $\mathrm{LFO}=$ low-flor & oxygen & & & & \\
\hline $\mathrm{OSA}=$ obstruct & e sleep apnea & & & & \\
\hline EELI $=$ end-ex $x_{1}$ & atory lung volume index & & & & \\
\hline $\mathrm{P}_{\mathrm{aw}}=$ airway $\mathrm{p}$ & & & & & \\
\hline $\mathrm{P} / \mathrm{F}=\mathrm{P}_{\mathrm{aO}} / / \mathrm{F}_{\mathrm{I}} \mathrm{O}$ & & & & & \\
\hline NYHA III $=\mathrm{N}$ & York Heart Association class III & & & & \\
\hline IVC $=$ inferior & na cava & & & & \\
\hline $\mathrm{ER}=$ emergenc & room & & & & \\
\hline $\mathrm{BFS}=$ broncho & ber scope & & & & \\
\hline $\mathrm{BMI}=$ body $\mathrm{m}$ & index & & & & \\
\hline $\mathrm{ns}=$ not signifi & & & & & \\
\hline na $=$ not availa & & & & & \\
\hline
\end{tabular}


of 20 were successfully treated with HFNC, and the 11 others were subsequently intubated. Lee et al ${ }^{63}$ retrospectively evaluated effects of HFNC for ARF in hematologic malignancies; HFNC treatment success rate was significantly different between the survivors and nonsurvivors. Subjects with bacterial pneumonia failed HFNC more frequently than others. ${ }^{63}$ Messika et al ${ }^{85}$ evaluated the indications and effects of HFNC in ARDS. When HFNC was applied as the first-line treatment, $40 \%$ of the subjects were subsequently intubated. HFNC failure was associated with high Simplified Acute Physiology Score II.

Whereas most of the published reports of HFNC in ARF are nonrandomized observational studies examining respiratory parameters during short follow-up periods, in the FLORALI study, ${ }^{10} \mathrm{ARF}$ subjects were randomly assigned to standard oxygen therapy, HFNC, or NIV. With HFNC, the intubation rate was 38\% (40 of 106 subjects); with standard oxygen therapy, the rate was $47 \%$ (44 of 94); and with NIV, it was $50 \%$ (55 of 110). Up to day 28 , the number of ventilator-free days was significantly greater with HFNC ( $24 \pm 8$ d) than with standard oxygen therapy $(22 \pm 10)$ or with NIV $(19 \pm 12) .{ }^{10}$ Comparing the effects of HFNC and bi-level positive airway pressure in subjects with ARF or high risk of developing ARF after cardiothoracic surgery, Stephan et al ${ }^{11}$ found treatment failure for 87 of 414 subjects (21.0\%) with HFNC and 91 of 416 with bi-level positive airway pressure $(21.9 \%)$. These studies suggest that HFNC oxygen therapy is a promising modality for early treatment of adults with severe ARF. However, intubation rates are as high as $30-50 \%$, we need more rigorous evidence to confidently guide our clinical choices and decide when it is necessary to escalate to intubation.

\section{Postextubation}

Re-intubation is associated with longer stays, both in the ICU and in hospital, and with greater mortality. ${ }^{86,87} \mathrm{HFNC}$ seems to improve oxygenation and reduce the need for escalation of respiratory support and re-intubation. ${ }^{64,70,73}$ Comparing HFNC and high-flow face mask delivery for extubated subjects, Tiruvoipati et $\mathrm{a}^{88}$ found no differences in respiratory and hemodynamic parameters between the modes, but tolerance of HFNC was better. Corley et al ${ }^{72}$ investigated whether HFNC after extubation could reduce postoperative atelectasis in subjects with a body mass in$\operatorname{dex} \geq 30 \mathrm{~kg} / \mathrm{m}^{2}$. They found no improvement of postoperative respiratory function with HFNC. HFNC did not necessarily improve postextubation respiratory failure in all subjects. We still await the findings of the OPERA trial, ${ }^{89}$ which is evaluating the effects of HFNC on postextubation hypoxemia following abdominal surgery.

\section{Preintubation Oxygenation}

Intubation in the ICU is often associated with significant complications..$^{90,91}$ To avoid complications during tracheal intubation, it is possible to apply NIV to enhance oxygenation. ${ }^{92}$ During laryngoscopy, however, the mask has to be removed; nasal cannulas, on the other hand, do not interfere with laryngoscopy, and HFNC could be used to deliver oxygen during the apneic period of tracheal intubation. A recent animal study has elegantly demonstrated how HFNC can significantly delay the occurrence of severe desaturation during apnea. ${ }^{43}$ In clinical trials designed to compare the effects of use of non-rebreathing bag reservoir face mask delivery and HFNC on pre- and peri-procedure oxygenation during tracheal intubation of ICU subjects, Miguel-Montanes et $\mathrm{a}^{193}$ found that with the non-rebreathing bag reservoir face mask, the median lowest $\mathrm{S}_{\mathrm{pO}_{2}}$ during intubation was $94 \%$, whereas, with HFNC, it was $100 \%$. The incidence of severe hypoxemia $\left(\mathrm{S}_{\mathrm{pO}_{2}}\right.$ $<80 \%)$ was significantly reduced with HFNC (14\% vs $2 \%) .{ }^{93}$ During intubation, the preponderance of published data clearly shows superior oxygenation by HFNC delivery. Vourc'h et al ${ }^{74}$ also found that the lowest $\mathrm{S}_{\mathrm{pO}_{2}}$ was higher with HFNC.

\section{Acute Heart Failure}

Various oxygenation methods are used for treating respiratory failure occurring with acute heart failure. ${ }^{94} \mathrm{HFNC}$ is a good alternative means of supplementing oxygenation. Examining the effect of HFNC on subjects with dyspnea and hypoxemia following NIV, Carratalá Perales et al ${ }^{22}$ found that all of their 5 subjects showed clinical improvement and were successfully treated with HFNC. Roca et al ${ }^{68}$ examined inferior vena cava collapse during inspiratory phase by echocardiography in subjects with New York Heart Association class III heart failure. HFNC decreased inspiratory collapse of the inferior vena cava, and it suggested that HFNC was supportive for subjects with severe heart failure. Moriyama et $\mathrm{al}^{57}$ have also reported successful maintenance of oxygenation in a patient with lifethreatening reperfusion pulmonary edema.

\section{Sleep Apnea}

OSA is attributed to upper airway collapse associated with intermittent hypoxemia, neurocognitive dysfunction, and cardiovascular morbidity. ${ }^{95-97}$ Although CPAP is held to be the most effective treatment, adherence is suboptimal. ${ }^{98}$ McGinley et al found that HFNC for OSA alleviated upper airway obstruction in children and that, both in children and adults, HFNC reduced arousals and apneahypopnea index ratings. ${ }^{67,99}$ Disordered breathing during sleep is also common among acute stroke patients and is 
associated with neurologic worsening and poor outcome. HFNC (18 L/min) was well-tolerated and decreased ratings both for apnea-hypopnea and oxygen desaturation: The percentage of slow-wave sleep significantly increased, and quality of sleep was better. ${ }^{100}$

\section{Other Conditions}

Hypoxemia is common during invasive procedures, and supplemental oxygen may be delivered by various interfaces. Testing HFNC during bronchoscopy in adults, Lucangelo et al ${ }^{71}$ compared the effects of $40 \mathrm{~L} / \mathrm{min}$ delivered via air-entrainment mask with HFNC of 40 and $60 \mathrm{~L} / \mathrm{min}$. At the end of the procedure, $\mathrm{HFNC}$ at $60 \mathrm{~L} / \mathrm{min}$ resulted in better oxygenation than $40 \mathrm{~L} / \mathrm{min}$ delivered either by airentrainment mask or by HFNC. Oxygenation was also better at $10 \mathrm{~min}$ after the completion of the procedure. ${ }^{71}$ Miyagi et al ${ }^{61}$ also applied HFNC during bronchoalveolar lavage in ARF. In a case reported by Diab and Fraser, ${ }^{55}$ HFNC effectively prevented hypoxemia in an orthotropic lung transplant recipient who required diagnostic bronchoscopy.

Patients with do-not-intubate status and respiratory failure are generally treated with NIV, ${ }^{101,102}$ which has been found effective in relieving sensations of dyspnea. HFNC may also be an effective alternative to NIV. Peters et al $^{37}$ assessed the efficacy of HFNC in do-not-intubate subjects with hypoxemic respiratory distress. Mean age was $73 \mathrm{y}$, and underlying diseases were pulmonary fibrosis, pneumonia, COPD, cancer, hematologic malignancy, and congestive heart failure. Only 9 of 50 subjects were escalated to NIV; $82 \%$ were maintained on HFNC. The median duration of HFNC was $30 \mathrm{~h} .{ }^{37}$ HFNC can provide adequate oxygenation for patients with hypoxemic respiratory failure and may be a more easily tolerated alternative to NIV for do-not-intubate patients.

Many clinical reports of HFNC use have been published. For example, Díaz-Lobato et al used HFNC to treat ARF of neuromuscular origin in a patient who could not tolerate NIV, ${ }^{60}$ and Boyer et al ${ }^{58}$ used it to treat pulmonary fibrosis for $>30 \mathrm{~d}$. Generally, over the long term, it is not possible to continuously support respiration with NIV. Byerly et al ${ }^{103}$ reported successfully using HFNC to treat a pediatric patient with inhalation injury, postextubation stridor, and a high risk of extubation failure. Calvano et al ${ }^{59}$ applied HFNC to a 92-y-old woman with delirium and dementia who was in the ICU for multi-lobar pneumonia with severe hypoxemia. After she had rejected various facial and nasal masks, it was found that she could tolerate HFNC. It reduced her agitation, ameliorated her dyspnea, improved oxygenation, and increased her comfort at the end of life.

\section{Adverse Effects}

With any noninvasive respiratory support, recourse to more invasive management may be delayed for patients with respiratory decompensation. Mechanical ventilation with endotracheal intubation is certainly more invasive than NIV, and tracheal intubation is regarded as an escalation when NIV fails. Is NIV in any sense more invasive than HFNC? Whereas HFNC delivers warm and humidified medical gas at high flow, it neither pushes respiratory gases into the lungs nor pulls gas from the lungs; consequently, it has been regarded as closely similar to standard oxygen therapy and judged accordingly. When HFNC was initially introduced for respiratory support, NIV was regarded as a more invasive or, at least, more powerful (or more forceful) treatment. HFNC was compared with standard oxygen therapy and, if HFNC failed, respiratory support was escalated to NIV. ${ }^{84}$

Since the introduction of HFNC, however, the diverse physiological effects of warm and humidified high-flow gas have become more apparent. To date, most of the published studies of HFNC in ARF have been nonrandomized observational studies examining differences in respiratory parameters during short follow-up periods. More recently, HFNC has been compared with NIV and been found to be at least not inferior to NIV with regard to intubation rate, ICU mortality, and ventilator-free days at day $28 .{ }^{10}$

In a comparison of postextubation respiratory failure, no difference was found between NIV and standard oxygenation therapy groups in the need for re-intubation. ICU mortality was higher in the NIV group (25\%) than in the standard therapy group (14\%), and the median time from respiratory failure to re-intubation was longer in the NIV group ( $12 \mathrm{~h}$ vs $2.5 \mathrm{~h}$ ). NIV does not prevent the need for re-intubation or reduce mortality in unselected subjects who have respiratory failure after extubation. ${ }^{104}$ Retrospectively assessing whether HFNC delayed intubation and had adverse effects, Kang et al ${ }^{65}$ found that using HFNC for longer than $48 \mathrm{~h}$ before intubation was associated with higher ICU mortality and less success at extubation and ventilator weaning, and fewer ventilator-free days. They examined all subjects who failed HFNC delayed and required intubation. In this retrospective observational study, all subjects failed HFNC, and 14- and 28-d mortality did not differ. The propensity-matching analysis carried out in this study did not fully evaluate the severity of conditions of the subjects. In another study, where there was exacerbation of COPD, 20\% failed NIV after an initial (first $48 \mathrm{~h}$ ) successful response, and the patients had a very poor in-hospital prognosis, especially if, instead of promptly initiating invasive ventilation, NIV was prolonged. ${ }^{105}$ Also, in de novo acute respiratory failure, NIV failure and delayed intubation worsened mortality. ${ }^{106}$ These studies have 
alerted us to the risk that inappropriate use of noninvasive respiratory support, including HFNC and NIV, may lead to adverse outcomes. Moreover, because HFNC is more comfortable for patients than NIV and can usually be tolerated for long periods, poor timing or overlooking the need to intubate might be even more likely.

Since delayed intubation may worsen the prognosis for patients treated with HFNC, the predictors of treatment failure are of special interest: one study identified failure of respiratory rate to decrease, poor oxygen saturation, and persisting thoraco-abdominal asynchrony as predictors of HFNC failure. ${ }^{39}$ Evaluating risk factors for intubation in lung transplantation recipients readmitted to the ICU, Roca et $\mathrm{al}^{62}$ identified indicators of standard oxygen therapy and HFNC failure to be respiratory parameters and higher systemic severity (estimated by sequential organ failure assessment and Acute Physiology and Chronic Health Evaluation [APACHE] II score) and the need for vasopressors. HFNC is widely applied to patients with diverse underlying diseases; naturally, the response to HFNC differs depending on the underlying diseases. Another important consideration is that, unlike standard oxygen therapy but in some ways similar to NIV, HFNC is an actually a powerful noninvasive respiratory support. When HFNC is unable to provide sufficient support, the patient is actually in a dangerous condition of respiratory failure. Sophisticated controlled trials are needed to identify criteria for timing intubation during HFNC. For now, however, we should carefully monitor the initial hour after starting HFNC: In patients successfully treated with HFNC, respiratory or hemodynamic parameters usually improve within $1 \mathrm{~h}$.

HFNC is an open ventilation system, yet it is still able to increase end-expiratory pressure. Pharyngeal pressure is affected by mouth-opening or closing, delivered flow, and size of nasal prongs. Usually, pharyngeal pressure is $<5 \mathrm{~cm} \mathrm{H}_{2} \mathrm{O}$; however, pressure is not predictable or sustained. Hedge and Prodhan ${ }^{107}$ reported 3 cases of serious air leaks related to HFNC therapy: right pneumothorax in a 2-month-old male with respiratory syncytial virus bronchiolitis receiving $8 \mathrm{~L} / \mathrm{min}$; pneumomediastinum in a 16y-old male with cerebral palsy receiving $20 \mathrm{~L} / \mathrm{min}$; and right pneumothorax in a 22-month-old previously healthy male with subdural hematoma receiving $6 \mathrm{~L} / \mathrm{min}$. Whereas pediatric ventilation systems incorporate safety valves to avoid high pressure, adult systems have neither a pressure release valve nor pressure monitors. Such complications could occur also in adults.

\section{Contraindication}

HFNC has been receiving more and more attention, and physicians have been applying it for a variety of diseases and conditions. In the absence of sufficient, well-estab- lished evidence or criteria for the clinical application of HFNC, absolute contraindications are also lacking. Mainly, prudent consideration is required before applying it for patients for whom NIV is contraindicated. When the main contraindication for NIV is claustrophobic sensations or intolerance of tight interface contact, HFNC is often a viable alternative.

\section{Conclusions}

HFNC oxygen delivery has already proved its value as an effective mode of noninvasive ventilatory support and has been gaining attention as a simple and well-tolerated alternative means of respiratory support for critically ill patients. Physicians have been using it for a wide variety of underlying diseases and conditions. It seems to be effective for treating hypercapnic respiratory failure and mild to moderate hypoxemic respiratory failure. We still need more rigorous evidence to establish some basic criteria, however, such as indications for HFNC, criteria for starting and stopping it, and indications for treatment escalation. Since HFNC is noninvasive, PEEP (CPAP) is not measured. Despite these issues, a growing body of evidence suggests that HFNC is an effective modality for early treatment of adults with respiratory failure associated with diverse underlying diseases.

\section{REFERENCES}

1. Rouadi P, Baroody FM, Abbott D, Naureckas E, Solway J, Naclerio RM. A technique to measure the ability of the human nose to warm and humidify air. J Appl Physiol 1999;87(1):400-406.

2. Chanques G, Constantin JM, Sauter M, Jung B, Sebbane M, Verzilli D, et al. Discomfort associated with underhumidified highflow oxygen therapy in critically ill patients. Intensive Care Med 2009;35(6):996-1003.

3. Fontanari P, Burnet H, Zattara-Hartmann MC, Jammes Y. Changes in airway resistance induced by nasal inhalation of cold dry, dry, or moist air in normal individuals. J Appl Physiol 1996;81(4):17391743.

4. Fontanari P, Zattara-Hartmann MC, Burnet H, Jammes Y. Nasal eupnoeic inhalation of cold, dry air increases airway resistance in asthmatic patients. Eur Respir J 1997;10(10):2250-2254.

5. Salah B, Dinh Xuan AT, Fouilladieu JL, Lockhart A, Regnard J. Nasal mucociliary transport in healthy subjects is slower when breathing dry air. Eur Respir J 1988;1(9):852-855.

6. L'Her E, Deye N, Lellouche F, Taille S, Demoule A, Fraticelli A, et al. Physiologic effects of noninvasive ventilation during acute lung injury. Am J Respir Crit Care Med 2005;172(9):1112-1118.

7. Markovitz GH, Colthurst J, Storer TW, Cooper CB. Effective inspired oxygen concentration measured via transtracheal and oral gas analysis. Respir Care 2010;55(4):453-459.

8. Bazuaye EA, Stone TN, Corris PA, Gibson GJ. Variability of inspired oxygen concentration with nasal cannulas. Thorax 1992; 47(8):609-611.

9. Nishimura M. High-flow nasal cannula oxygen therapy in adults. J Intensive Care 2015;3(1):15. 
10. Frat JP, Thille AW, Mercat A, Girault C, Ragot S, Perbet S, et al. High-flow oxygen through nasal cannula in acute hypoxemic respiratory failure. N Engl J Med 2015;372(23):2185-2196.

11. Stéphan F, Barrucand B, Petit P, Rézaiguia-Delclaux S, Médard A, Delannoy B, et al. High-flow nasal oxygen vs noninvasive positive airway pressure in hypoxemic patients after cardiothoracic surgery: A randomized clinical trial. JAMA 2015;313(23):2331-2339.

12. Parke RL, McGuinness SP. Pressures delivered by nasal high flow oxygen during all phases of the respiratory cycle. Respir Care 2013; 58(10):1621-1624.

13. Girou E, Brun-Buisson C, Taillé S, Lemaire F, Brochard L. Secular trends in nosocomial infections and mortality associated with noninvasive ventilation in patients with exacerbation of COPD and pulmonary edema. JAMA 2003;290(22):2985-2991.

14. Nava S, Cirio S, Fanfulla F, Carlucci A, Navarra A, Negri A, Ceriana P. Comparison of two humidification systems for longterm noninvasive mechanical ventilation. Eur Respir J 2008;32(2): 460-464

15. Nagata K, Morimoto T, Fujimoto D, Otoshi T, Nakagawa A, Otsuka $\mathrm{K}$, et al. Efficacy of high-flow nasal cannula therapy in acute hypoxemic respiratory failure: decreased use of mechanical ventilation. Respir Care 2015;60(10):1390-1396.

16. Hirsch JA, Tokayer JL, Robinson MJ, Sackner MA. Effects of dry air and subsequent humidification on tracheal mucous velocity in dogs. J Appl Physiol 1975;39(2):242-246.

17. Chidekel A, Zhu Y, Wang J, Mosko JJ, Rodriguez E, Shaffer TH. The effects of gas humidification with high-flow nasal cannula on cultured human airway epithelial cells. Pulm Med 2012;2012: 380686.

18. Barbet JP, Chauveau M, Labbé S, Lockhart A. Breathing dry air causes acute epithelial damage and inflammation of the guinea pig trachea. J Appl Physiol 1988;64(5):1851-1857.

19. Berk JL, Lenner KA, McFadden ER Jr. Cold-induced bronchoconstriction: role of cutaneous reflexes vs. direct airway effects. J Appl Physiol 1987;63(2):659-664.

20. Van Oostdam JC, Walker DC, Knudson K, Dirks P, Dahlby RW, Hogg JC. Effect of breathing dry air on structure and function of airways. J Appl Physiol 1986;61(1):312-317.

21. Campbell EJ, Baker MD, Crites-Silver P. Subjective effects of humidification of oxygen for delivery by nasal cannula: a prospective study. Chest 1988;93(2):289-293.

22. Carratalá Perales JM, Llorens P, Brouzet B, Albert Jiménez AR, Fernández-Cañadas JM, Carbajosa Dalmau J, et al. High-flow therapy via nasal cannula in acute heart failure. Rev Esp Cardiol 2011; 64(8):723-725.

23. Koutsourelakis I, Vagiakis E, Perraki E, Karatza M, Magkou C, Kopaka M, et al. Nasal inflammation in sleep apnoea patients using CPAP and effect of heated humidification. Eur Respir J 2011;37(3): 587-594.

24. Oto J, Imanaka H, Nishimura M. Clinical factors affecting inspired gas humidification and oral dryness during noninvasive ventilation. J Crit Care 2011;26(5):535.e9-535.e15.

25. Wood KE, Flaten AL, Backes WJ. Inspissated secretions: a lifethreatening complication of prolonged noninvasive ventilation. Respir Care 2000;45(5):491-493.

26. Doyle A, Joshi M, Frank P, Craven T, Moondi P, Young P. A change in humidification system can eliminate endotracheal tube occlusion. J Crit Care 2011;26(6):637.e1-e4.

27. Greenspan JS, Wolfson MR, Shaffer TH. Airway responsiveness to low inspired gas temperature in preterm neonates. J Pediatr 1991; 118(3):443-445.

28. Rea H, McAuley S, Jayaram L, Garrett J, Hockey H, Storey L, et al. The clinical utility of long-term humidification therapy in chronic airway disease. Respir Med 2010;104(4):525-533.
29. Tobin MJ, Mador MJ, Guenther SM, Lodato RF, Sackner MA. Variability of resting respiratory drive and timing in healthy subjects. J Appl Physiol 1988;65(1):309-317.

30. Chikata Y, Izawa M, Okuda N, Itagaki T, Nakataki E, Onodera M, et al. Humidification performance of two high-flow nasal cannula devices: a bench study. Respir Care 2014;59(8):1186-1190.

31. Chikata Y, Unai K, Izawa M, Okuda N, Oto J, Nishimura M. Condensation in the tube during high-flow nasal cannula therapy: a bench study. Respir Care 2016;61(3):300-305.

32. Navalesi P, Fanfulla F, Frigerio P, Gregoretti C, Nava S. Physiologic evaluation of noninvasive mechanical ventilation delivered with three types of masks in patients with chronic hypercapnic respiratory failure. Crit Care Med 2000;28(6):1785-1790.

33. Conti G, Antonelli M, Navalesi P, Rocco M, Bufi M, Spadetta G, Meduri GU. Noninvasive vs. conventional mechanical ventilation in patients with chronic obstructive pulmonary disease after failure of medical treatment in the ward: a randomized trial. Intensive Care Med 2002;28(12):1701-1707.

34. Gregoretti C, Confalonieri M, Navalesi P, Squadrone V, Frigerio P, Beltrame F, et al. Evaluation of patient skin breakdown and comfort with a new face mask for non-invasive ventilation: a multi-center study. Intensive Care Med 2002;28(3):278-284.

35. Collins CL, Barfield C, Horne RS, Davis PG. A comparison of nasal trauma in preterm infants extubated to either heated humidified high-flow nasal cannulae or nasal continuous positive airway pressure. Eur J Pediatr 2014;173(2):181-186.

36. Schwabbauer N, Berg B, Blumenstock G, Haap M, Hetzel J, Riessen R. Nasal high-flow oxygen therapy in patients with hypoxic respiratory failure: effect on functional and subjective respiratory parameters compared to conventional oxygen therapy and non-invasive ventilation (NIV). BMC Anesthesiol 2014;14:66.

37. Peters SG, Holets SR, Gay PC. High-flow nasal cannula therapy in do-not-intubate patients with hypoxemic respiratory distress. Respir Care 2013;58(4):597-600.

38. Itagaki T, Okuda N, Tsunano Y, Kohata H, Nakataki E, Onodera $\mathrm{M}$, et al. Effect of high-flow nasal cannula on thoraco-abdominal synchrony in adult critically ill patients. Respir Care 2014;59(1): 70-74.

39. Sztrymf B, Messika J, Bertrand F, Hurel D, Leon R, Dreyfuss D, Ricard JD. Beneficial effects of humidified high flow nasal oxygen in critical care patients: a prospective pilot study. Intensive Care Med 2011;37(11):1780-1786.

40. Sztrymf B, Messika J, Mayot T, Lenglet H, Dreyfuss D, Ricard JD. Impact of high-flow nasal cannula oxygen therapy on intensive care unit patients with acute respiratory failure: a prospective observational study. J Crit Care 2012;27(3):324.e9-13.

41. Roca O, Riera J, Torres F, Masclans JR. High-flow oxygen therapy in acute respiratory failure. Respir Care 2010;55(4):408-413.

42. Corley A, Caruana LR, Barnett AG, Tronstad O, Fraser JF. Oxygen delivery through high-flow nasal cannulae increase end-expiratory lung volume and reduce respiratory rate in post-cardiac surgical patients. Br J Anaesth 2011;107(6):998-1004.

43. Frizzola M, Miller TL, Rodriguez ME, Zhu Y, Rojas J, Hesek A, et al. High-flow nasal cannula: impact on oxygenation and ventilation in an acute lung injury model. Pediatr Pulmonol 2011;46(1):67-74.

44. Lavizzari A, Veneroni C, Colnaghi M, Ciuffini F, Zannin E, Fumagalli $\mathrm{M}$, et al. Respiratory mechanics during NCPAP and $\mathrm{HH}-$ HFNC at equal distending pressures. Arch Dis Child Fetal Neonatal Ed 2014;99(4):F315-F320.

45. Saslow JG, Aghai ZH, Nakhla TA, Hart JJ, Lawrysh R, Stahl GE, Pyon KH. Work of breathing using high-flow nasal cannula in preterm infants. J Perinatol 2006;26(8):476-480.

46. de Jongh BE, Locke R, Mackley A, Emberger J, Bostick D, Stefano $\mathrm{J}$, et al. Work of breathing indices in infants with respiratory in- 
sufficiency receiving high-flow nasal cannula and nasal continuous positive airway pressure. J Perinatol 2014;34(1):27-32.

47. Pham TM, O'Malley L, Mayfield S, Martin S, Schibler A. The effect of high flow nasal cannula therapy on the work of breathing in infants with bronchiolitis. Pediatr Pulmonol 2015;50(7):713-720.

48. Benchetrit G. Breathing pattern in humans: diversity and individuality. Respir Physiol 2000;122(2):123-129.

49. Ritchie JE, Williams AB, Gerard C, Hockey H. Evaluation of a humidified nasal high-flow oxygen system, using oxygraphy, capnography and measurement of upper airway pressures. Anaesth Intensive Care 2011;39(6):1103-1110.

50. Wettstein RB, Shelledy DC, Peters JI. Delivered oxygen concentrations using low-flow and high-flow nasal cannulas. Respir Care 2005;50(5):604-609.

51. Lampland AL, Plumm B, Meyers PA, Worwa CT, Mammel MC. Observational study of humidified high-flow nasal cannula compared with nasal continuous positive airway pressure. J Pediatr 2009;154(2):177-182.

52. Parke R, McGuinness S, Eccleston M. Nasal high-flow therapy delivers low level positive airway pressure. Br J Anaesth 2009; 103(6):886-890.

53. Groves N, Tobin A. High flow nasal oxygen generates positive airway pressure in adult volunteers. Aust Crit Care 2007;20(4):126131.

54. Riera J, Pérez P, Cortés J, Roca O, Masclans JR, Rello J. Effect of high-flow nasal cannula and body position on end-expiratory lung volume: a cohort study using electrical impedance tomography. Respir Care 2013;58(4):589-596.

55. Parke RL, Bloch A, McGuinness SP. Effect of very-high-flow nasal therapy on airway pressure and end-expiratory lung impedance in healthy volunteers. Respir Care 2015;60(10):1397-1403.

56. Diab S, Fraser JF. Maintaining oxygenation successfully with high flow nasal cannula during diagnostic bronchoscopy on a postoperative lung transplant patient in the intensive care. Case Rep Crit Care 2014;2014:198262.

57. Moriyama K, Satoh T, Motoyasu A, Kohyama T, Kotani M, Kanai $\mathrm{R}$, et al. High-flow nasal cannula therapy in a patient with reperfusion pulmonary edema following percutaneous transluminal pulmonary angioplasty. Case Rep Pulmonol 2014;2014:837612.

58. Boyer A, Vargas F, Delacre M, Saint-Léger M, Clouzeau B, Hilbert G, Gruson D. Prognostic impact of high-flow nasal cannula oxygen supply in an ICU patient with pulmonary fibrosis complicated by acute respiratory failure. Intensive Care Med 2011;37(3):558-559.

59. Calvano TP, Sill JM, Kemp KR, Chung KK. Use of a high-flow oxygen delivery system in a critically ill patient with dementia. Respir Care 2008;53(12):1739-1743.

60. Díaz-Lobato S, Folgado MA, Chapa A, Mayoralas Alises S. Efficacy of high-flow oxygen by nasal cannula with active humidification in a patient with acute respiratory failure of neuromuscular origin. Respir Care 2013;58(12):e164-e167.

61. Miyagi K, Haranaga S, Higa F, Tateyama M, Fujita J. Implementation of bronchoalveolar lavage using a high-flow nasal cannula in five cases of acute respiratory failure. Respir Investig 2014;52(5): 310-314.

62. Roca O, de Acilu MG, Caralt B, Sacanell J, Masclans JR. Humidified high flow nasal cannula supportive therapy improves outcomes in lung transplant recipients readmitted to the intensive care unit because of acute respiratory failure. Transplantation 2015;99(5): 1092-1098.

63. Lee HY, Rhee CK, Lee JW. Feasibility of high-flow nasal cannula oxygen therapy for acute respiratory failure in patients with hematologic malignancies: a retrospective single-center study. J Crit Care 2015;30(4):773-777.
64. Brotfain E, Zlotnik A, Schwartz A, Frenkel A, Koyfman L, Gruenbaum SE, Klein M. Comparison of the effectiveness of high flow nasal oxygen cannula vs. standard non-rebreather oxygen face mask in post-extubation intensive care unit patients. Isr Med Assoc J 2014;16(11):718-722.

65. Kang BJ, Koh Y, Lim CM, Huh JW, Baek S, Han M, et al. Failure of high-flow nasal cannula therapy may delay intubation and increase mortality. Intensive Care Med 2015;41(4):623-632.

66. Nilius G, Franke KJ, Domanski U, Rühle KH, Kirkness JP, Schneider $\mathrm{H}$. Effects of nasal insufflation on arterial gas exchange and breathing pattern in patients with chronic obstructive pulmonary disease and hypercapnic respiratory failure. Adv Exp Med Biol 2013;755:27-34.

67. McGinley B, Halbower A, Schwartz AR, Smith PL, Patil SP, Schneider H. Effect of a high-flow open nasal cannula system on obstructive sleep apnea in children. Pediatrics 2009;124(1):179188.

68. Roca O, Pérez-Téran P, Masclans JR, Pérez L, Galve E, Evangelista A, Rello J. Patients with New York Heart Association class III heart failure may benefit with high flow nasal cannula supportive therapy: high flow nasal cannula in heart failure. J Crit Care 2013; 28(5):741-746.

69. Lenglet H, Sztrymf B, Leroy C, Brun P, Dreyfuss D, Ricard JD. Humidified high flow nasal oxygen during respiratory failure in the emergency department: feasibility and efficacy. Respir Care 2012; 57(11):1873-1878.

70. Parke R, McGuinness S, Dixon R, Jull A. Open-label, phase II study of routine high-flow nasal oxygen therapy in cardiac surgical patients. Br J Anaesth 2013;111(6):925-931.

71. Lucangelo U, Vassallo FG, Marras E, Ferluga M, Beziza E, Comuzzi L, et al. High-flow nasal interface improves oxygenation in patients undergoing bronchoscopy. Crit Care Res Pract 2012;2012: 506382.

72. Corley A, Bull T, Spooner AJ, Barnett AG, Fraser JF. Direct extubation onto high-flow nasal cannulae post-cardiac surgery versus standard treatment in patients with a BMI $\geq 30$ : a randomised controlled trial. Intensive Care Med 2015;41(5):887-894.

73. Maggiore SM, Idone FA, Vaschetto R, Festa R, Cataldo A, Antonicelli $\mathrm{F}$, et al. Nasal high-flow versus Venturi mask oxygen therapy after extubation: effects on oxygenation, comfort, and clinical outcome. Am J Respir Crit Care Med 2014;190(3):282-288.

74. Vourc'h M, Asfar P, Volteau C, Bachoumas K, Clavieras N, Egreteau PY, et al. High-flow nasal cannula oxygen during endotracheal intubation in hypoxemic patients: a randomized controlled clinical trial. Intensive Care Med 2015;41(9):1538-1548.

75. Dewan NA, Bell CW. Effect of low flow and high flow oxygen delivery on exercise tolerance and sensation of dyspnea: a study comparing the transtracheal catheter and nasal prongs. Chest 1994; 105(4):1061-1065.

76. Brochard L, Mancebo J, Wysocki M, Lofaso F, Conti G, Rauss A, et al. Noninvasive ventilation for acute exacerbations of chronic obstructive pulmonary disease. N Engl J Med 1995;333(13):817822.

77. Ozyilmaz E, Ugurlu AO, Nava S. Timing of noninvasive ventilation failure: causes, risk factors, and potential remedies. BMC Pulm Med 2014;14:19.

78. Nicolini A, Ferrera L, Santo M, Ferrari-Bravo M, Del Forno M, Sclifò F. Noninvasive ventilation for hypercapnic exacerbation of chronic obstructive pulmonary disease: factors related to noninvasive ventilation failure. Pol Arch Med Wewn 2014;124(10):525531.

79. Millar J, Lutton S, O'Connor P. The use of high-flow nasal oxygen therapy in the management of hypercarbic respiratory failure. Ther Adv Respir Dis 2014;8(2):63-64. 
80. Bräunlich J, Beyer D, Mai D, Hammerschmidt S, Seyfarth HJ, Wirtz $\mathrm{H}$. Effects of nasal high flow on ventilation in volunteers, COPD and idiopathic pulmonary fibrosis patients. Respiration 2013; 85(4):319-325.

81. Chatila W, Nugent T, Vance G, Gaughan J, Criner GJ. The effects of high-flow vs low-flow oxygen on exercise in advanced obstructive airways disease. Chest 2004;126(4):1108-1115.

82. Kelly GS, Simon HK, Sturm JJ. High-flow nasal cannula use in children with respiratory distress in the emergency department: predicting the need for subsequent intubation. Pediatr Emerg Care 2013;29(8):888-892.

83. Rittayamai N, Tscheikuna J, Praphruetkit N, Kijpinyochai S. Use of high-flow nasal cannula for acute dyspnea and hypoxemia in the emergency department. Respir Care 2015;60(10):1377-1382.

84. Rello J, Pérez M, Roca O, Poulakou G, Souto J, Laborda C, et al. High-flow nasal therapy in adults with severe acute respiratory infection: a cohort study in patients with 2009 influenza A/H1N1v. J Crit Care 2012;27(5):434-439.

85. Messika J, Ben Ahmed K, Gaudry S, Miguel-Montanes R, Rafat C, Sztrymf B, et al. Use of high-flow nasal cannula oxygen therapy in subjects with ARDS: a 1-year observational study. Respir Care 2015;60(2):162-169.

86. Torres A, Gatell JM, Aznar E, el-Ebiary M, Puig de la Bellacasa J, González J, et al. Re-intubation increases the risk of nosocomial pneumonia in patients needing mechanical ventilation. Am J Respir Crit Care Med 1995;152(1):137-141.

87. Esteban A, Anzueto A, Frutos F, Alía I, Brochard L, Stewart TE, et al. Characteristics and outcomes in adult patients receiving mechanical ventilation: a 28-day international study. JAMA 2002;287(3): 345-355.

88. Tiruvoipati R, Lewis D, Haji K, Botha J. High-flow nasal oxygen vs high-flow face mask: a randomized crossover trial in extubated patients. J Crit Care 2010;25(3):463-468.

89. Futier E, Paugam-Burtz C, Constantin JM, Pereira B, Jaber S. The OPERA trial: comparison of early nasal high flow oxygen therapy with standard care for prevention of postoperative hypoxemia after abdominal surgery: study protocol for a multicenter randomized controlled trial. Trials 2013;14:341.

90. Schwartz DE, Matthay MA, Cohen NH. Death and other complications of emergency airway management in critically ill adults: a prospective investigation of 297 tracheal intubations. Anesthesiology 1995;82(2):367-376.

91. Mort TC. Emergency tracheal intubation: complications associated with repeated laryngoscopic attempts. Anesthesia Analgesia 2004; 99(2):607-613, table of contents.

92. Baillard C, Fosse JP, Sebbane M, Chanques G, Vincent F, Courouble $\mathrm{P}$, et al. Noninvasive ventilation improves preoxygenation before intubation of hypoxic patients. Am J Respir Crit Care Med 2006;174(2):171-177.

93. Miguel-Montanes R, Hajage D, Messika J, Bertrand F, Gaudry S, Rafat $\mathrm{C}$, et al. Use of high-flow nasal cannula oxygen therapy to prevent desaturation during tracheal intubation of intensive care patients with mild-to-moderate hypoxemia. Crit Care Med 2015; 43(3):574-583.

94. Masip J, Betbesé AJ, Páez J, Vecilla F, Cañizares R, Padró J, et al. Non-invasive pressure support ventilation versus conventional oxygen therapy in acute cardiogenic pulmonary oedema: a randomised trial. Lancet 2000;356(9248):2126-2132.

95. Cortuk M, Akyol S, Baykan AO, Kiraz K, Ucar H, Cayli M, et al. Aortic stiffness increases in proportion to the severity of apnoeahypopnea index in patients with obstructive sleep apnoea syndrome. Clin Respir J 2014. doi: 10.111/crj.12244.

96. Sahlin C, Sandberg O, Gustafson Y, Bucht G, Carlberg B, Stenlund $\mathrm{H}$, Franklin KA. Obstructive sleep apnea is a risk factor for death in patients with stroke: a 10-year follow-up. Arch Intern Med 2008; 168(3):297-301.

97. Fonseca MI, Pereira T, Caseiro P. Death and disability in patients with sleep apnea: a meta-analysis. Arq Bras Cardiol 2015;104(1): 58-66.

98. Marcus CL, Rosen G, Ward SL, Halbower AC, Sterni L, Lutz J, et al. Adherence to and effectiveness of positive airway pressure therapy in children with obstructive sleep apnea. Pediatrics 2006;117(3): e442-e451.

99. McGinley BM, Patil SP, Kirkness JP, Smith PL, Schwartz AR, Schneider H. A nasal cannula can be used to treat obstructive sleep apnea. Am J Respir Crit Care Med 2007;176(2):194-200.

100. Haba-Rubio J, Andries D, Rey-Bataillard V, Michel P, Tafti M, Heinzer R. Effect of transnasal insufflation on sleep-disordered breathing in acute stroke. Sleep Breath 2015;19(1):3.

101. Schettino G, Altobelli N, Kacmarek RM. Noninvasive positive pressure ventilation reverses acute respiratory failure in select "do-notintubate" patients. Crit Care Med 2005;33(9):1976-1982.

102. Levy M, Tanios MA, Nelson D, Short K, Senechia A, Vespia J, Hill NS. Outcomes of patients with do-not-intubate orders treated with noninvasive ventilation. Crit Care Med 2004;32(10):2002-2007.

103. Byerly FL, Haithcock JA, Buchanan IB, Short KA, Cairns BA. Use of high flow nasal cannula on a pediatric burn patient with inhalation injury and post-extubation stridor. Burns 2006;32(1):121-125.

104. Esteban A, Frutos-Vivar F, Ferguson ND, Arabi Y, Apezteguía C, González $\mathrm{M}$, et al. Noninvasive positive-pressure ventilation for respiratory failure after extubation. N Engl J Med 2004;350(24): 2452-2460.

105. Moretti M, Cilione C, Tampieri A, Fracchia C, Marchioni A, Nava S. Incidence and causes of non-invasive mechanical ventilation failure after initial success. Thorax 2000;55(10):819-825.

106. Carrillo A, Gonzalez-Diaz G, Ferrer M, Martinez-Quintana ME, Lopez-Martinez A, Llamas N, et al. Non-invasive ventilation in community-acquired pneumonia and severe acute respiratory failure. Intensive Care Med 2012;38(3):458-466.

107. Hegde S, Prodhan P. Serious air leak syndrome complicating highflow nasal cannula therapy: a report of 3 cases. Pediatrics 2013; 131(3):e939-e944. 